\title{
Risk Management in Case of Egg Allergy
}

\author{
Koch A, Wollina U* \\ Department of Dermatology and Allergology,Academic Teaching Hospital Dresden-Friedrichstadt, Germany
}

Received: November 16, 2016; Accepted: December 15, 2016; Published: December 29, 2016

*Corresponding author: Prof. Dr. U. Wollina, Department of Dermatology and Allergology, Academic Teaching Hospital Dresden-Friedrichstadt, Friedrichstrasse 41,01067 Dresden, Germany.E-mail: wollina-uw@khdf.de

\begin{abstract}
Food-related allergies are of clinical importance. Their diagnostics covers a significant part of allergology clinic's work. Allergic reactions to egg proteins are frequently diagnosed among children but remain uncommon among adult patients. We report on two cases of adult patients presenting with allergies to egg proteins, ovalbumin and ovomucoid. In case of ovalbumin allergy, hen`s eggs and quail egg's are a source of the thermolabile antigen. In contrast, ovomucoid is heat-resistant. Molecular allergy diagnostics support the risk management of patients with suspected egg allergy.
\end{abstract}

Keywords: Food allergy; Egg proteins; Ovalbum; Ovomucoid; Molecular Allergy Diagnositics; Risk Management;

\section{Introduction}

Food allergies are reported by our patients with increasing frequency. Diagnostics and care for foood allergic patients reperesent a significant percentage of workload in the allergy clinic. Here, we will focus on egg-related allergies.

Hen eggs (Domus domesticus) are an important protein source for human nutrition. Eggs and egg components are part of various foods like mayonnaise, pasta, pastries, sausages, glazes, salads, convenience food, and confectionary.

Egg allergies are predominantly seen during the first years of live. Up to $2 \%$ of children and adolescents are affected [1-4]. Hen's eggs and cow milk are the most important food allergens in childhood [2, 3]. Due to tolerance induction with increasing age, the percentage of hen's egg allergies declines among adults to only $12 \%$ of all food allergies [2-4].

Clinical symptoms can vary by severity and organs affected. Symptomatology includes gastro-intestinal complaints, dyspnoea, cutaneous reactions, and anaphylactic shock. The severity of an allergic reaction depends upon sensitization, allergen amount, and type of exposure [4]. The variability of clincial signs and symptoms is a challenge for the allergologist to advise patients in risk management.

In recent years, molecular diagnostics in allergology have become reality. By detailed knowledge of relevant allergens in complex allergen sources such as food, a tailored risk management is facilitated.
The major known allergens of hen's eggs are ovalbumin, conalbumin, ovomucoid, and lysozyme [1-4].

With the following case reports we want to illustrate modern risk management in food allergies.

\section{Case Report}

Case 1: A 54-year-old female patient experienced lip swelling, nausea and thoracic pressure immediately after lunch. The meal consisted of quail eggs - sunny side up-, mashed potatoes, red cabbage, pasta with tomato sauce, and beer. Medical emergency treatment was successful.

In consequence of this event she avoided quail eggs, the only new food component. Hen's eggs were consumed by the patient only hard boiled, what was well tolerated.

After detailed medical history, we performed prick tests with the foods. The prick test for native hen's egg was positive (Fig. 1). Laboratory investigations demonstrated specific IgE against ovalbumin $0.88 \mathrm{kUA} / \mathrm{l}$ (CAP-class 2), but not against any other egg component.

Case 2: A 40-year-old female patient reported about pharyngeal tingling sensations and abdominal pain after consumption of boiled eggs for years. After detailed medical history a prick test was performed, that revealed a positive reaction to native hen's egg. Laboratory investigated disclosed specific IgE against ovalbumin (0.77 kUA/l, CAP-class 2) and ovomucoid (0.49 kUA/l, CAP-class 1$)$.

Limitations: Double-blinded oral provocation is used for confirmation of food allergies. However, in practise, not all patients will agree to perform the oral challenge. Both of our patients refused oral provocation, since they remained without further allergic reactions to egg proteins after diagnostics and counselling.

\section{Discussion}

Egg allergies can usually be confirmed by the combination of medical history, prick test, and specific IgE. Prick test with native hen's egg is more sensitive that with commercial egg extracts $[4,5]$. It must be kept in mind that different assays for specific IgE provide variable, not uniformous results considering the absolute values. In case of follow-up to verify immune tolerance development, the same assay should be used [6]. 
Egg allergens are often hidden allergens in food. An investigation of snacks and pastries identified undeclared egg allergens in $12 \%$ and $6 \%$ of cases [7]. That is a source of discomfiture among consumers. Egg allergies rank on foremost position for smaller children in the Germany Anaphylaxis Registry [8].

Molecular allergy represents a milestone the diagnostic of food allergies. For the first time, tailored risk profiles can be assessed for individual patients. Patients can be counselled accordingly to avoid the identified allergens or to prepare the food - in case of thermolabile allergens - in a proper way. This will reduce the risk of severe allergic reactions [9]. A limitation is, however, that most clinical trials have been performed in small children, not adults.

Case 1 demonstrates cross-reactivity of egg allergens among different bird species. Hen (Gallus domesticus) and quail (Coturnix coturnix) belong to the same family of Galliformes. The known major allergens of hen's eggs are ovomucoid (Gal d 1), ovalbumin (Gal d 2), ovotransferrin (Gal d 3), lysozyme (Gal d 4), and albumin (Gal d 5). Proteins with the highest sensitizing potential can be found rather in the white egg (Gal d 1-4) compared to egg yolk (Gal d 5) [1-4].

Ovalbumin represents $54 \%$ of egg proteins [1-4, 9]. Ovalbumin ist thermo-labile. A fried egg - sunny side up - had enough native ovalbumin to induce an allergic reaction in patient \#1. Hard boild eggs or deeply fried eggs don't imposes a risk for the patients [2, 4], illustrated nicely by the symptless consumption of hard boild hen's eggs in case 1 .

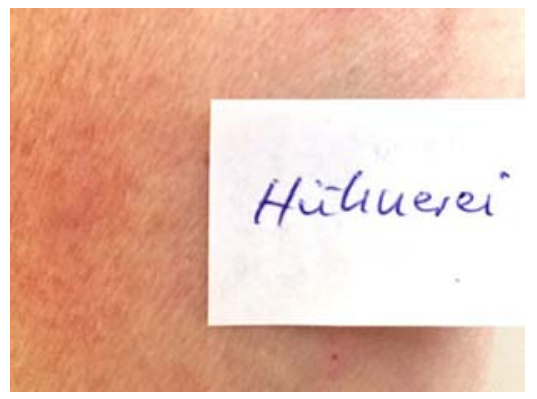

Figure 1: Positive skin prick test with native hen's egg (Hühnerei)

Table 1: Pros and Cons of Molecular Diagnostics

Pros and Cons of Molecular Diagnostics

\begin{tabular}{|l|l|}
\hline Pros & Cons \\
\hline $\begin{array}{l}\text { Defined single molecules without } \\
\text { contamination with sensitizing side } \\
\text { chains }\end{array}$ & $\begin{array}{l}\text { Not all relevant antigens are } \\
\text { available yet }\end{array}$ \\
\hline Standardisation & Production delicat \\
\hline $\begin{array}{l}\text { Identification of individual } \\
\text { sensitization patterns }\end{array}$ & $\begin{array}{l}\text { Polymorphism of natural allergen } \\
\text { extracts is difficult to recreate }\end{array}$ \\
\hline $\begin{array}{l}\text { Differentiation between genuine } \\
\text { sensitization and cross-reactivity }\end{array}$ & Interpretation needs experience \\
\hline Higher specificity and sensitivity & Higher costs \\
\hline
\end{tabular}

In contrast, ovomucoid is thermo-stabile and resistant to digestion. Ovalbumin is the dominant allergen component of hen's eggs and represents $11 \%$ of hen's eggs protein amount [3, 4]. The protein can be identified in small amounts not only in food but vaccines against yellow fever and influenca. This might theoretically cause problems in highly sensitized patients. A Japanese study investigated the risk of influenca vaccination in children allergic to eggs but could not find any allergic reactions to the vaccine [10].

Low-level specific IgE against ovomucoid may be a hint for mild symptoms after consumption of boiled eggs as in case 2 or of tolerance induction. A failure of tolerance development is often associated with increased specific IgE againts ovomucoid [5].

There is a case report of a child without hen's egg allergy who developed food-protein enterocolitis syndrome after consumption of quail eggs. Such reaction is not IgE mediated. Due to diarrhoea and vomiting allergic shock can be seen in up to 20 $\%$ of patients [11].

Patients with ovomucoid-allergy are not protected by food processing. Strict avoidance of eggs or oral tolerance induction are the alternatives. Recently, monoclonal IgE antibody omalizumab has been used off-label in such cases [12].

\section{References}

1. Rona RJ, Keil T, Summers C, Gislason D, Zuidmeer L, Sodergren E, et al. The prevalence of food allergy: a meta-analysis. J Allergy Clin Immunol. 2007;120(3):638-646.

2. Mine Y, Zhang JW. Comparative studies on antigenicity and allergenicity of native and denatured egg white proteins. J Agric Food Chem. 2002;50(9):2679-2683.

3. Poulsen LK, Hansen TK, Norgaard A, Vestergaard H, Stahl Skov P, Bindslev-Jensen C. Allergens from fish and egg. Allergy. 2001;56(Suppl 67):39-42.

4. Urisu A, Kondo Y, Tsuge I. Hen's egg allergy. Chem Immunol Allergy. 2015;101:124-130. doi: 10.1159/000375416.

5. Gray CL, Levin ME, du Toit G. Egg sensitization, allergy and component patterns in African children with atopic dermatitis. Pediatr Allergy Immunol. 2016;27(7):709-715. doi: 10.1111/pai.12615

6. Furuya K, Nagao M, Sato Y, Ito S, Fujisawa T; IPAD3g investigators. Predictive values of egg-specific IgE by two commonly used assay systems for the diagnosis of egg allergy in young children: a prospective multicenter study. Allergy. 2016;71(10):1435-1443. doi: 10.1111/all.12912

7. Khuda SE, Sharma GM, Gaines D, Do AB, Pereira M, Chang M, et al. Survey of undeclared egg allergen levels in the most frequently recalled food types (including products bearing precautionary labelling). Food Addit Contam Part A Chem Anal Control Expo Risk Assess. 2016;33(8):1265-1273. doi: 10.1080/19440049.2016.1198051.

8. Worm M, Grünhagen J, Dölle S. Anaphylaktische Reaktionen auf Lebensmittel - Daten aus dem Anaphylaxie-Register. Bundesgesundheitsblatt Gesundheitsforschung Gesundheitsschutz. 2016;59(7):836-840.

9. Dang TD, Mills CE, Allen KJ. Determination of the clinical egg allergy phenotypes using component-resolved diagnostics. Pediatr Allergy Immunol. 2014;25(7):639-643. 
10. Shimizu M, Imai T, Yamazaki S, Yagawa A, Miyazawa T, Nakamura T, et al. Safety of influenca vaccination in children with severe allergy to hen's eggs: A prospective case series study. Arerugi. 2016;65(2):128133. doi: 10.15036/arerugi.65.128.

11. Sanlidag B, Babayigit Hocaoglu A, Bahceciler N. Quail's egg-induced severe enterocolitis in a child tolerant to hen's egg: first reported case.
J Investig Allergol Clin Immunol. 2016;26(2):118-119. doi: 10.18176/ jiaci.0024.

12. Martorell A, Alonso E, Boné J, Echeverría L, López MC, Martín F, et al. Position document: IgE-mediated allergy to egg protein. Allergol Immunopathol (Madr). 2013;41(5):320-336. doi: 10.1016/j. aller.2013.03.005 